\title{
Recoding in a mediation condition
}

\author{
JERAL R. WILLIAMS \\ Illinois State University, Normal, Ilinois 61761
}

\begin{abstract}
When subjects were asked to recall Stage 2 after completion of Stage 3 learning in a modified A-B, B-C, A-C mediated interference condition, they made reliably more errors than subjects in facilitation and control conditions. The majority of the errors were intrusions of the mediational B-C associations that had been re-paired during Stage 3 . The errors were assumed to be evidence for recoding of memory traces for B-C associative events. Thus, a mediation paradigm which has historically been closely related to associative viewpoints was useful for the study of recoding.
\end{abstract}

Recoding has been conceptualized in several ways (e.g., Martin, 1972; Massaro, 1975). Tulving and Thomson (1973) have described recoding as an active modification of stored information. The present research involved investigating whether recoding could occur in a three-stage mediation condition using Tulving and Thomson's concept of recoding. Three-stage mediation was used for methodological reasons and because, as Schulz (1972) has recently argued, the understanding of mediation paradigms should be expanded to integrate both associative and cognitive viewpoints.

In an A-B, B-C, A-C condition, subjects can utilize the memory traces for $\mathrm{B}-\mathrm{C}$ events to perform A-C. If the mediated B-C associations during Stage 3 are re-paired to form a mediated interference condition, subjects could recode the stored memory traces for the Stage 2 events to be in agreement with the re-paired associations in order to perform Stage 3. The latter strategy would be particularly useful for subjects if the A-B list involved several stimuli paired with a single response. Evidence of recoding would be a particular type of error in recall of the Stage 2 associations following Stage 3 learning. That is, if a subject's errors were in agreement with the re-paired mediational associations (i.e., intrusions), recoding of the Stage 2 associations could be assumed. Therefore, the primary present concern was to see if intrusions occurred in a mediated interference condition.

\section{METHOD}

\section{Design}

All subjects performed four tasks. Stage 1 was a pairedassociate task with 16 low $-\bar{m}$ dissyllables (Noble, 1952) as stimuli and four common nouns as responses. Stage 2 consisted of a four-choice sorting task in which subjects learned to sort cards, on which nouns were typed, into correct slots on a wooden panel. Stage 3 consisted of a sorting procedure in which subjects sorted cards on which Stage 1 dissyllables were typed into correct slots. The fourth task (Recall) was recall of Stage 2 .

Three between-subjects conditions were defined by variations in the $A-B, B-C, A-C$ paradigm. The first was a facilitationfacilitation (FF) group, in which the Stage 1 and Stage 2 associa-

This paper is sponsored by Gordon M. Redding, who takes full editorial responsibility for its contents. tions were in agreement with an assumed Stage 3 chain of associations (i.e., A-B, B-C, A-C). The second was a facilitationneutral (FN) group, in which the Stage 1 associations were appropriate but the Stage 2 associations were neutral for a Stage 3 chain of associations (i. e., A-B, X-C, A-C). The third was a facilitation-interference (FI) group, in which the Stage 1 associations were appropriate but the Stage 2 associations were re-paired mediationally for Stage 3 performance (i.e., A-B, $\left.\mathrm{B}-\mathrm{C}_{\mathrm{r}}, \mathrm{A}-\mathrm{C}\right)$.

\section{Subjects}

The subjects were 30 general psychology students who received credit for participation. Ten individual subjects were assigned by block randomization to each of the three groups.

\section{Materials}

For Stage 1, two separate 16-item paired-associate lists were generated for presentation on a Stowe memory drum by using two different sets of four common nouns as responses. In each list, four of the dissyllables were associated individually to each of the nouns. Thus, each noun appeared four times within any given study order. Three random study-test orders for each list were developed for presentation across trials.

In Stages 2 and 3, a wooden panel in which four horizontal slots were cut was used for sorting $7.62 \times 12.70 \mathrm{~cm}$ index cards. Each slot had a light over it which was used for corrective feedback. In Stage 2 nouns were typed on cards, while in Stage 3 the dissyllables from Stage 1 were typed on cards. The Stage 2 materials were used for Recall.

\section{Procedure}

The subjects in Stage 1 were asked to learn a paired-associate list, by the study-test method, to a criterion of 16 correct responses in a single test trial. Each of the two lists was presented to an equal number of subjects. One of the three study orders for each list was randomly assigned as a starting position to subjects within a group. The item presentation and intertrial intervals were 2 sec. During the test trials, the subjects were presented the dissyllables and were asked to pronounce the appropriate noun.

In Stage 2 the subjects were given a deck of 24 cards (i. e., six block randomized orders of the four different nouns). For the subjects in FF and FI the nouns were the response items from Stage 1. In FN the nouns were an alternate set of Stage 1 response items. Subjects pronounced a noun, and then placed a card in one of the slots. The experimenter then administered corrective feedback by lighting a light over the correct slot. The subjects were self-paced, with the restriction that a card not be sorted until feedback had been given for the preceding card. Stage 2 was performed until each subject had correctly sorted the four nouns on three consecutive trials.

Stage 3 was similar to Stage 2, except that there were 64 
Table 1

Performance on Stages 1, 2, 3, and Recall for Subjects in FF, FN, and FI

\begin{tabular}{|c|c|c|c|c|c|}
\hline \multirow{2}{*}{\multicolumn{2}{|c|}{ Condition }} & \multicolumn{2}{|c|}{$\begin{array}{c}\text { Trials } \\
\text { to Criterion }\end{array}$} & \multirow{3}{*}{$\begin{array}{c}\text { Total } \\
\text { Correct } \\
\text { Stage } 3 \\
119.40 \\
9.61\end{array}$} & \multirow{3}{*}{$\begin{array}{c}\begin{array}{c}\text { Total } \\
\text { Errors } \\
\text { Recall }\end{array} \\
0\end{array}$} \\
\hline & & Stage 1 & Stage 2 & & \\
\hline FF & $\begin{array}{l}\text { Mean } \\
\text { SD }\end{array}$ & $\begin{array}{r}10.50 \\
4.24\end{array}$ & $\begin{array}{l}5.40 \\
1.35\end{array}$ & & \\
\hline FN & $\begin{array}{l}\text { Mean } \\
\text { SD }\end{array}$ & $\begin{array}{l}8.90 \\
3.17\end{array}$ & $\begin{array}{r}4.20 \\
.60\end{array}$ & $\begin{array}{l}83.60 \\
27.31\end{array}$ & 2.60 \\
\hline FI & $\begin{array}{l}\text { Mean } \\
\text { SD }\end{array}$ & $\begin{array}{r}10.50 \\
3.07\end{array}$ & $\begin{array}{l}5.90 \\
2.34\end{array}$ & $\begin{array}{l}82.70 \\
21.16\end{array}$ & 14.40 \\
\hline
\end{tabular}

cards (i. e., four orders for 16 dissyllables). Corrective feedback was again given, but the task was performed until each subject had sorted the deck of cards twice. The recall task was performed with the same procedures as Stage 2, except that no corrective feedback was given and each subject sorted the entire deck of 24 cards.

\section{RESULTS}

Simple analyses of variance of trials to criterion (see Table 1) comparing all three conditions on Stages 1 and 2 did not, in either instance, yield a significant effect $[F<1$ for Stage 1, and $F(2,27)=2.68, p>.05$ for Stage 2]. However, since the FF and FI conditions were the conditions in which negative transfer on Stage 2 was expected (e.g., Schulz, Weaver, \& Ginsberg, 1965), an additional analysis was performed. A t test comparing 23 errors in the FN condition to the 38 and 39 errors for the combined FF and FI conditions was significant $[\mathrm{t}(28)=2.15, \mathrm{p}<.05]$.

In Stage 3 , as expected by a mediational analysis, the means for number correct were ordered (most to least) FF, FN, FI (see Table 1). The planned comparison of $F F$ to $F N$ was significant $[F(1,27)=13.42, p<.05]$. Thus, subjects appear to have been utilizing the B-C events during Stage 3. The planned comparison of FN to FI was nonsignificant, $F<1$. Thus, the re-pairing of B-C associations did not hinder subjects' performance more than formation of a new association.

The errors during recall of Stage 2 were ordered (least to most) FF, FN, FI (see Table 1). A comparison of the distribution of errors for the three conditions relative to chance revealed a significant effect on each of the six trials $[\chi(2)=27.72,40.20,35.43,35.43$, 35.43 , and $35.43, \mathrm{p}<.05$, respectively]. Clearly, the subjects in FI were making a higher proportion of errors than subjects in the other conditions. For the FI subjects, evidence for recoding would be the intrusion of re-paired noun-slot associations that were learned mediationally during Stage 3. A total of 101 of the 144 errors in FI were intrusions. A comparison of the distribution of intrusions relative to a chance distribution of errors approached significance on Trial 1 and was significant on Trials $2-6[\chi(1)=3.71, .10>p>.05$, and $\chi(1)=10.13,11.21,13.65,10.13$, and 11.36, $\mathrm{p}<.05$, respectively]

\section{DISCUSSION}

The intrusions in the FI condition during recall of the B-C associations, in conjunction with the mediated facilitation on Stage 3 for the FF condition, support the notion that active modification of stored information can be studied in traditional mediation conditions. The methodological strength of the present procedures is that recoding processes would appear to be separable from encoding and retrieval processes.

The intrusions would not seem to be due to Stage 2 encoding differences because, during Stage 2 , subjects in FF and FI studied the B-C associations under similar encoding conditions. Thus, the differences in retrieval during recall are apparently due to some process that happened after Stage 2. Since the B-C associations are not presented overtly during Stage 3, the process could not be initial encoding.

Retrieval strategies which could account for intrusions are not as easily separable. One retrieval scheme which could account for intrusions without recoding begins with the assumption that subjects in FI may have utilized stored memory traces of the response items of Stage 1 to perform Stage 3. Further, it would have to be assumed that, even though nominal responses of Stage 1 were identical to the nominal stimuli for Stage 2, the stored memory traces for the B items were different. Thus, the present intrusions would be due to retrieval "confusion" between different memory traces for the identical B items, rather than to recoding of the Stage 2 memory traces.

Such an interpretation can be countered by considering that, if in all three conditions subjects independently stored the B items on Stages 1 and 2, then there would be no reason to expect negative transfer on Stage 2 for the FF and FI conditions. The evidence for negative transfer on Stage 2 was limited to the error analysis but, when the evidence is viewed in conjunction with the simplicity of the task, the conclusion of negative transfer is strengthened. Additionally, retrieval confusion resulting in intrusions depends on the assumption that when subjects are presented $B$ items under conditions similar to Stage 2, they retrieve the $B$ items that were coded as Stage 1 responses. The latter assumption, although possible, is against the notion that an important factor in retrieval is similarity of encoding cues present at storage and retrieval. Thus, although the evidence and arguments are limited, the retrieval account that subjects stored the B items independently and intrusions resulted from confusion of traces was not accepted.

\section{REFERENCES}

Martin, E. Stimulus encoding in learning and transfer. In A. W. Melton \& E. Martin (Eds.), Coding processes in human memory. Washington, D. C.: Winston, 1972.

MASSARO, D. W. Experimental psychology and information processing. Chicago: Rand-McNally, 1975.

Noble, C. E. An analysis of meaning. Psychological Review, 1952, 59, 421-430.

Schulz, R. W. Mediation. In C. P. Duncan, L. Sechrest, \& A. W. Melton (Eds.) Human memory: Festschrift in honor of Benton J. Underwood. New York: Appleton-Century-Crofts, 1972.

Schulz, R. W., Weaver, G. E., \& Ginsberg, S. Mediation with pseudomediation controlled: Chaining is not an artifact! Psychonomic Science, 1965, 2, 169-170.

Tulving, E., \& Thomson, D. M. Encoding specificity and retrieval processes in episodic memory. Psychological Review, 1973, 80, 352-373. 